\title{
Analysis and Countermeasures on Arabic Students' Quantifier Misuse in Learning Chinese as a Second Language: From a Comparative Linguistic Perspective
}

\author{
Wang Jinhua
}

\author{
School of Humanities and Social Sciences, University of Science and Technology of China, Hefei, Anhui 230026, \\ China \\ *Corresponding author. Email: wjh329@mail.ustc.edu.cn
}

\begin{abstract}
Abundant in Chinese language, quantifier is considered as a difficult point in learning Chinese as a second language for Arabic students whose mother tongue comes from a different language system. This essay statistically analyzes the quantifier misuse that Arabic students made based on the corpus. By comparing Chinese and Arabic languages in grammar and the different expressions on the concept of number from the perspective of cognitive linguistic, it can be found that factors, including mother tongue negative transfer, teaching methods, textbooks, students as well as cultural backgrounds, weigh heavily in quantifier misuse. This essay aims to explore the countermeasures for Chinese teaching and learning from the view of quantifier misuse that Arabic students make and proposes to provide supports for Arabic students' understanding and learning of quantifiers.
\end{abstract}

Keywords: quantifier misuse, Chinese and Arabic languages comparison, cognitive linguistic, factors, countermeasures, Chinese teaching and learning

\section{INTRODUCTION}

Chinese and Arabic belong to two different language systems, the former falling into Sino-Tibetan language family and the later Semitic-Hamitic language family, in which the expression of concept in number varies in grammar. Chinese embraces abundant quantifiers in various quantitative phrase collocations which are concerned with its grammar and cultural background that mirrors the nation's unique perception and cognition towards the world. However, even for most Chinese people, it is hard to explain the usage among numerous quantifiers, instead, they regard it as an unutterable conventional practice. Also, most quantifiers in textbooks are explained in semantic fuzziness or semantic absolute, which creates doubts for those who learn Chinese as a second language. Quantifiers are classified into two types - noun quantifiers and verb quantifiers, which can be further divided into four branches including special noun quantifiers, temporary noun quantifiers, special verb quantifiers and temporary verb quantifiers [i]. Furthermore, special noun quantifiers consist of three parts covering individual quantifiers, collective quantifiers as well as weights and measures quantifiers.
In the same way, special verb quantifiers are separated into two types - one is measurements of times, the other is temporal duration [1]. In contrast, Arabic language lacks quantifiers and differs in word order compared with Chinese. Combined with cognitive linguistic, this essay aims to analyze the factors of quantifier misuse through comparing Chinese and Arabic language systems. Also, in light of the difference and relation between Chinese and Arabic, this essay further proposes to put up countermeasures for better teaching and learning Chinese as a second language.

\section{ILLUSTRATION OF QUANTIFIER MISUSE OF ARABIC STUDENTS}

Based on the quantifiers selected from HSK textbooks[ii], this research targets on Arabic students whose Chinese levels range from HSK4-HSK6 and adopted survey as the research method. This essay will analyze the factors of quantifier misuse in learning Chinese as a second language by the following chart (Table 1) from the perspective of Chinese-Arabic language systems comparison as well as cognitive linguistic. 
Table 1 Classification of the quantifier misuse in survey

\begin{tabular}{|l|c|c|c|c|c|c|c|}
\hline $\begin{array}{l}\text { classification } \\
\text { of quantifier } \\
\text { misuse }\end{array}$ & $\begin{array}{l}\text { lack of } \\
\text { quantifiers }\end{array}$ & $\begin{array}{l}\text { redundancy } \\
\text { of } \\
\text { quantifiers }\end{array}$ & $\begin{array}{l}\text { homophonous } \\
\text { quantifiers }\end{array}$ & $\begin{array}{l}\text { synonymous } \\
\text { quantifiers }\end{array}$ & $\begin{array}{l}\text { quantifiers } \\
\text { modifying } \\
\text { abstract } \\
\text { nouns } \\
\text { when } \\
\text { concerning } \\
\text { images }\end{array}$ & $\begin{array}{l}\text { generalization } \\
\text { of “个” }\end{array}$ & $\begin{array}{l}\text { word } \\
\text { order }\end{array}$ \\
\hline frequency & 52 & 48 & 76 & 82 & 65 & 27 & 86 \\
\hline $\begin{array}{l}\text { misuse } \\
\text { ratios(specific } \\
\text { type of } \\
\text { quantifier } \\
\text { misuse in total } \\
\text { number of } \\
\text { misuse) }\end{array}$ & $11.93 \%$ & $11 \%$ & $17.43 \%$ & $18.81 \%$ & $14.91 \%$ & $6.2 \%$ & $19.72 \%$ \\
\hline
\end{tabular}

As presented above, the quantifier misuse mainly falls in word order, synonymous quantifiers as well as homophonous quantifiers, in which this essay would illustrate in detail in the following:

Word order misuse mainly results from the different grammars between Chinese and Arabic language systems. (All the English quantifiers below 2-4 are literal English translation version, as there is no equivalent expression in English. And all the sentences with "*” are wrong in Chinese language)

e.g. 1.*转了他给我一笔钱昨天。(Transferred he me a sum of money yesterday-Arabic version).

昨天他给我转了一笔钱。(Yesterday he transferred me a sum of money.-Chinese)

2.*拿了妈妈一把伞出门了。(Took mom a handful of umbrella went outside.-Arabic version)

*出门了妈妈一把伞拿了。(Went outside mom a handful of umbrella took.-Arabic version)

妈妈拿了二把伞出门了。(Mom took a handful of umbrella and went outside.-Chinese)

3.*夺走了疫情一场生命许多人的。(Taken away epidemic a round of lives many-Arabic version)

一场疫情夺走了许多人的生命。( A round of epidemic has taken away many lives.-Chinese)

4.*他是怎么人? ( He is how person?-Arabic version)

*他是什么二个人? (He is what a person?-Arabic version)

*他是一个怎么人? (He is $\underline{\mathbf{a}}$ how person?-Arabic version)

他是怎么二个人? (He is how a person?-Chinese)

他是一个什么人? (He is $\underline{\mathbf{a}}$ what person?-Chinese)
Word order takes up the largest part in quantifier misuse, with $19.72 \%$ in total. Arabic students tend to organize the sentences in structure of Verb + Subject + Object + Adverbial, which accords with the word order of Arabic language ${ }^{[i i i]}$. But in Chinese, Subject + Verb + Object is a common structure, and adverbial is comparatively flexible. Also in Arabic language, there is no concept of quantifier, students can hardly know the order of a quantifier collocation in the whole sentence. Above 1-3 examples illustrate that Arabic students are confused with word order in Chinese, especially when sentences concerning with quantifiers. Example 4 is a difficult teaching point, as these sentences concern with the usage of “怎么” and “什么” with quantifier collocations. In Chinese, “他是一个什么人” and “他是 怎么一个人” are correct in expression of "what kind of person he is".

Arabic students also tend to make mistakes in distinguishing synonymous quantifiers. Almost this type of misuse covers the different Chinese levels, from initial to advanced stage, accounting for the second largest proportion of $18.81 \%$ in total misuse. Even those Arabic students who have passed the HSK6 examination still have problems in usage of the seeming easy quantifiers.(All the English quantifiers below are literal English translation version, as there is no equivalent expression in English.)

e.g. 1. 它的外形像一头 (条) 蛇, 头上还有一双 (对) 龙角。

(Its appearance resembles a head of (strip of) snake, and there is a pair of (couple of) dragon horns on the head.)

Arabic students tend to use "头 (a head of)" to describe a snake, but its synonymy “条(a strip of)” is more accepted in Chinese, as “条” highlights the long and thin shape of objects in Chinese people's cognition. In the same way, “一双(a pair of)” and “一对(a couple of)” can hardly be clearly explained for their difference to many Chinese people, but they are applied in separate contexts. In Chinese, we use “一对龙角” rather than “一双龙角”. 
2.吃完饭，我带同学去了一遍（趟）附近的商场,她 买了两件（条）裙子和一条（件）大衣。

(After lunch, I went once (took a trip) to the nearby shopping mall with my classmate, and she bought two pieces of (strips of ) skirts and a strip of (piece of ) overcoat.)

“遍(times)” and “趟(take a trip)” both belong to verb quantifiers, and they calculate the action times from one starting point to a destination repeatedly. But “遍” emphasizes the integrity of whole action process, while " 趟” implies spatial displacement in Chinese, such as “去 了一趟商场” rather than “去了一遍商场”. Also, Arabic students have troubles in describing clothing with quantifiers, such as “两条裙子” and “一件大衣”, and “ 两件裙子” and “一条大衣” are considered wrong collocations in Chinese expression.

\section{3. 他是在我二十年的生活中, 最喜爱最尊敬的一位} （个）人。

(He is the (a) man I respect most during the 20 years of my life.)

Although “位(the)" is defined as a respectful measure word for people ${ }^{[2]}$, it can not be applied before “人 (people)" directly, so “一位人” is a wrong quantifier collocation. Instead, “位” collocates with people's identity, jobs, titles, etc. But Arabic students may easily misuse this quantifier collocation in reference of English notes in textbooks. “一个人” is proper in Chinese rather than “一位人”.

4. 上午加班, 下午看赛马, 她太累了, 所以她觉 得自己的这副/片 (张) 脸很难看。

(As having worked overtime in the morning and watched the horse racing in the afternoon, she felt exhausted and looked awful on this pair of/ sheet of (piece of) face.)

In Chinese, “这张脸(this piece of face)” and “这副面 孔(this pair of countenance)" are correct in expression, while “这副脸(this pair of face)” and “这片脸(this sheet of face)" are deemed as wrong collocations.

\section{5.她买了一根/条（节）电池。}

\section{She bought a stick of/ strip of (section of ) battery.}

From the perspective of Arabic students, “一根 (a stick of)”, “一条(a strip of)” and “一节(a section of)” are synonymous quantifiers as these three quantifiers all embrace the meaning of long and thin objects, so Arabic students can hardly distinguish among them. However, " 一根” and “一条” highlights the integrity of an object, while “一节” refers to a section of an object short in length. Therefore, “一节电池” is correct in Chinese expression rather than “一根电池” or “一条电池”.
Hardly telling difference among those Chinese characters with the same pronunciation but different radicals, many Arabic students easily drop into the trap in homophonous quantifier misuse with $17.43 \%$ in total, as they can hardly distinguish radicals in Chinese characters with the same pronunciation. Examples are listed below (All the English quantifiers below are literal English translation version, as there is no equivalent expression in English):

\section{e.g. 1. 他的那幅（副）面孔让我感到很熟悉。}

\section{(I am familiar with his scroll of (pair of) face.)}

“幅” and “副” both have the same pronunciation in Chinese of "Fu", and share the same radical part. Some Arabic students have doubts in their quantifier collocations as they do not master homophonous quantifiers themselves, so they make mistakes for “那幅 面孔”, while “那副面孔” is correct in Chinese expression as “幅(a scroll of)” is commonly used to describe paintings or calligraphy.

\section{2.他的车撞到了一颗（棵）树上。}

\section{(His car crashed into a particle of (plant of) tree.)}

In this sentence, “颗(a particle of)” and “棵(a plant of)" both pronounce as "ke" in Chinese, and vary in different contexts. “棵” is closely connected with plants as it has the radical of “木(wood)”. Thus in Chinese, “一 棵树(a plant of tree)" is a correct quantifier collocation.

Overpowered by habitual thinking, Arabic students who have reached the intermediate level of Chinese language often make mistakes in quantifier collocations concerning modifying the abstract nouns when concerning Chinese images in expression. This type of misuse takes up $14.91 \%$ in total, and it is considered as the bottleneck for most Arabic students after a period of Chinese learning. (All the English quantifiers below are literal English translation version, as there is no equivalent expression in English):

\section{e.g. 1. 在这件事上, 咱们俩是一颗（条）心。}

(We are a particle of (strip of) mind on this thing.)

In fact, “一颗心 (a particle of mind)" and “一条心 (a strip of mind)" are both correct Chinese expression, but vary in context application. “一颗心” literally means heart with the image of round shape, while “一条心” implies the Chinese image of strengthened relationship between two parties. Arabic students would like to choose "一颗心” in this sentence, as the quantifier “颗” in is defined as describing things small and roundish ${ }^{[2]}$. However, “在这件事上 (on this thing)” puts forward a context, so “一条心” is proper in this sentence.

\section{2. 龙现在已经成为中华文化的一个(种)精神力量。}


(Dragon now has become a one (kind of) spiritual power in Chinese culture.)

Most Arabic students choose “一个精神力量 (one spiritual power)" because they hesitate on the abstract noun “精神力量”,

Other types of quantifier misuse including lack or redundancy of quantifiers and generalization of “个” are common phenomenon for Arabic students, and Chinese language teachers have gradually taken them seriously in teaching.

\section{FACTORS OF QUANTIFIER MISUSE}

From the perspective of Arabic students, the difference in grammar system between Chinese and Arabic languages is the major factor that results in misuse of word order and lack of quantifiers. It is necessary to compare the features of these two languages:

1) Arabic language belongs to typical inflectional language, so the change of forms conveys the different grammatical meaning. Also, as roots in Arabic language represent the grammar functions by the change of forms, word order in Arabic language is comparatively flexible. However, Chinese belongs to isolated language and lacks form variation, where word order and functional words play the key role in grammar $^{[\mathrm{iv}]}$.

e.g. 雪白一件衣服（snow white a piece of clothing） is different from 二件雪白的衣服 (a piece of snow white clothing) in semantic meaning, as the former one emphasize “雪白”(snow white), while the later one pertains to the normal attribute-center structure ${ }^{[\mathrm{v}]}$.

2) There is no quantifier in Arabic language, and a figure followed by a noun represents the concept of number. e.g. 两只猫 (Chinese) ; 两猫 (Arabic version). On the contrast, although Chinese do not distinguish the concept of figure in form variation, it does have a clear noun quantifier classification, such as individual quantifiers, collective quantifiers, weights and measures quantifiers, as well as temporary quantifiers in special noun quantifiers, and special verb quantifiers, etc.

3) In Arabic language, the modifiers appear behind the modified parts, while the situation in Chinese is in the opposite direction.

e.g. 一场疫情夺走了许多人的生命。(A round of epidemic has taken away many lives.-Chinese)

*夺走了疫情一场生命许多人的。(Taken away epidemic a round of lives many-Arabic version)

4) “什么”(what) and “怎么” (how) have the same implication in Arabic language, so it is difficult for them to identify true or false of these sentences:*他是怎么人?(He is how person?); *他是什么一个人?(He is what a person?); *他 是一个怎么人?(He is a how person?); 他是怎 么一个人? (He is how a person?); 他是一个 什么人? (He is a what person?)

However, they vary both in meanings and usage in Chinese. “什么 (what)” and “怎么 (how)” are complementary with each other when they play the role of attributes, as the modified part can not embrace quantitative components in “什么 (what)"collocation, while the situation is opposite in “怎么 (how)” collocation $^{[\mathrm{vi}]}$. Also, “怎么” can not directly be the attribute of a noun ${ }^{[\text {vii] }}$, so “他是怎么人?” is a wrong sentence.

5) The word order in Arabic language follows the rule of endocentric construction ${ }^{\text {[viii] }}$, that is, VSO structure, which is different from Chinese of SVO structure.

e.g. 昨天他给我转了一笔钱。(Yesterday he transferred me a sum of money_Chinese)

*转了他给我一笔钱昨天。(Transferred he me a sum of money yesterday-Arabic version).

妈妈拿了一把伞出门了。(Mom took an umbrella and went outside.-Chinese).

*拿了妈妈一把伞出门了。(Took mom an umbrella went outside.-Arabic version)

*出门了妈妈一把伞拿了。(Went outside mom an umbrella took-Arabic version)

The word order in Arabic language can be shown in the following chart (Table 2): from the center to the outward layer, the sequence is Verb-Subject-ObjectAdverbials (State-Degree-Duration-Location-Reason and Purpose). In Arabic language, verb is considered as the core, and other components are distributed according to the closeness with verb ${ }^{[4]}$

Table $2^{[4]}$

Endocentric Structure of Sentence Elements in Arabic Language

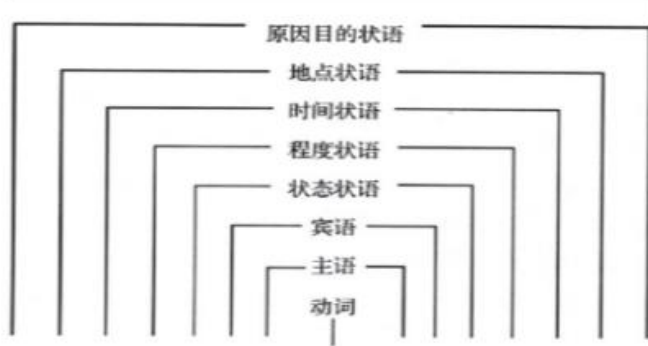

It is also worthy of notice that English explanatory notes for most quantifiers in HSK textbooks are not 
precise nor comprehensive, which limits their use and understanding in communicative context. Arabic students can hardly truly master the synonymous ones after learning merely based on English notes.

e.g. “件” in HSK textbooks is defined as piece, which is used for clothes and other items, and “条” is used for pants and dresses in notes ${ }^{[2]}$, which result in the mistakes in this sentence: 吃完饭, 我带同学去了趟附近的商 场，她买了两件（条）裙子和一条（件）大衣。(After lunch, I took a trip to the nearby shopping mall with my classmate, and she bought two pieces of (strips of ) skirts and a strip of (piece of ) overcoat.)

Arabic students can not differentiate between “条” and “件” by the English explanation, and other quantifiers encounter the same problems, such as “副”, “双”, “对” and "俩". These four quantifiers all have the shared features of two items. But why do they differentiate in specific collocations? Because these synonymous quantifiers have their own cognitive prototypes and extended implications through metaphor. “条” refers to tree branches, so its cognitive prototype embrace these features: long and thin branches; elastic and flexible ${ }^{[i x]}$. And “裙子” (skirt) sculptures the legs' long and thin contour, so “两条裙子 (two strips of skirts)” fits the context above. But “件” implies in the context of clothing or abstract things with integrity and independence ${ }^{[\mathrm{x}]}$. As “大衣” (overcoat) covers the whole body, it represents integrity to some degree. So in Chinese, “一件大衣( piece of overcoat)" is a habitual expression. Also, we take “双”, “对”, “副” and “俩” as another example. As they all convey the meaning of two objects, most Arabic students are confused in usage. In Chinese language, we use “一对夫妻” ( a pair of couple), “一对龙角” ( of dragon horns) not “一双夫妻” or “一双龙角”, and use “一副碗筷” (a set of dishes) not “一双碗筷” or “一对碗 筷". From the perspective of cognitive linguistic, the family resemblance of “双” connects limbs and organs, such as “一双手” (a pair of hand), “一双腿” ( legs), “一双鞋”( a pair of shoes) or “一双袜子”( of socks), while “对” emphasizes the coordination between two objects that follows the rule of unity of opposites, such as “一对夫妻” (a pair of couple-male and female), “一对手镯”( right hand) or “一对矛盾”(a pair of contradictionsopposite directions) $\left.{ }^{[\mathrm{xi}}\right]$. Furthermore, the family resemblance of “副” highlights the two parts in symmetry, two different items in cooperation, or multifunctions among different parts as one unity ${ }^{[11]}$, such as “一副眼镜” (a pair of glasses-two glasses in symmetry), “二副手套” (a pair of gloves-left and right hands in symmetry), “二副碗筷”( chopsticks, a bowl and a spoon) or “二副手镯” (a pair of bracelets-left and right hands in symmetry). These four quantifiers function in a braided relationship. Overall, it is textbook itself creates the doubts of synonymous quantifier usage.

The Chinese images and Arabic students' confusion in Chinese characters also should be attached with great importance, as these two factors both concern with Chinese people's cognition towards the world. The Chinese images permeate in quantifier usage, demanding a profound understanding of Chinese cultural connotation, which is also a headache even for Chinese people, since most of the time they can only use synonymous quantifiers and those modifying abstract nouns correctly out of their language sense.

e.g. 咱们俩是一颗（条）心。We are a grain of ( strip of ) mind on this thing.

\section{一颗心脏（a grain of heart）}

In this sentence, although “颗” usually describes particles or rounded objects such as “一颗心脏(a grain of heart)”, it can not be applied in “咱们俩是一颗心(we are a grain of mind)", because this sentence highlights the strengthened relations between two parties. “条” implies a long tie image, so “一条心(a strip of mind)” creates the image of united as one compared with “一颗心(a strip of mind)".

\section{e.g. 龙现在已经成为中华民族的一个 (种) 精神力} 量。(Dragon now has become a one (kind of) spiritual power in Chinese culture.)

The quantifier “种” in Chinese originates from the meaning of classification of nouns, and its cognitive foundation is the image of "seed". From the perspective of cognitive linguistic, "seed" is an internal factor that distinguishes various species and extends the implication of classification by metonymy ${ }^{[\mathrm{xii}]}$. And the individual quantifier “种” mainly applies to unbounded items ${ }^{[5]}$. “精 神力量(spiritual power)" is an abstract noun pertaining to unbounded phrase. “力量 (power)" can be further divided into kinds of powers, so “一种精神力量(a kind of spiritual power)" fits the context.

In the same way, homophonous quantifiers in Chinese such as “副(fu)” and “幅(fu)”, “棵(ke)” and “颗(ke)” are considered as a difficult point for Arabic students, especially for those beginners, because Arabic language consists of alphabets, while Chinese characters are composed of phonetic and radical parts.

e.g. “棵” has the radical part of “木”(wood)”, so this quantifier in Chinese people's cognition is connected with plants, such as “一棵树”(a plant of tree), while “颗 "refers to objects in round shape at a comparatively small size, such as “一颗心”(

“副” refers to pair of items, such as eye-glasses, while “幅” has the radical part of “巾”, which is connected with 
fabric and paper in Chinese traditional culture, such as “ 一幅画”(one scroll of painting).

What's more, generalization of “个” is mainly caused by Chinese teachers' misguidance, as they prefer to taking it as the cure-all for most quantifier collocations, which makes sense to some extent in oral expression but results in the generalization in different contexts.

\section{TEACHING ADVICE}

First, it is important for Chinese language teachers to emphasize the structure of quantifier collocations. As there is no concept of quantifier in Arabic language, it is necessary to highlight the structure of "figure + quantifier + noun" when describing the specific quantities. Otherwise, figures would turn into imaginary number when concerning the demonstrative pronouns such as “那 (that) +个（one）+人（person）” and “这（this）+把 (handful) +椅子 (chairs) ". Also, teaching quantifiers from the cognitive perspective lays a foundation for a better understanding of learning Chinese as a second language. The imagery cognition and semantic cognition

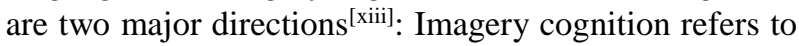
the teaching method of showing objects, pictures, and then extending to abstract things with similar characteristics in image ${ }^{[13]}$. e.g. When teaching “条(a strip of)", a Chinese teacher lists some quantifier collocations such as “一条领带(a strip of tie)”, “一条河 (a strip of river)” and “几条小鱼(several strips of fishes)” with pictures or objects, and guide students to summarize the common feature of “条” — an object in long and thin shape. Thus, students can deduce that “一条心(a strip of mind)”, varying from “一颗心(a grain of heart)”, is applied in the context of strengthening the relationship between two parties. Semantic cognition highlights dating back from original meanings of quantifiers and exploring the relations with the modified parts in semantic $^{[13]}$, such as the example taken above to explain “种”, whose cognitive foundation is "seed" and it functions as classification of items一龙现在已经成为中 华民族的一种精神力量。(Dragon now has become a kind of spiritual power in Chinese nation.) Therefore, filling students with relative Chinese culture is recommended as an auxiliary way. Chinese language teachers should tell students that the semantic of quantifiers extends based on the traditional Chinese things which demands accumulative knowledge towards Chinese cultural background and Chinese characters. Then, Chinese language teachers should explain one specific quantifier clearly to avoid generalization or ambiguous definition that appears in HSK textbooks, instead, teachers should design targeted practice to strengthen Arabic students' memory of quantifiers learning, such as substitution drills and some funny activities combined with chin-fun acoustic images to arouse students' interests and to penetrate their cognition towards meanings and usage of quantifiers.

From the perspective of Arabic students, it is necessary to overcome their mother tongue's negative transfer on the one side. Arabic students have to recognize the distinctive features of Chinese quantifier collocations in semantic and structure which are absent in Arabic language when expressing the concept of number. As Chinese and Arabic languages belong to two different language systems, students should build up their confidence to overcome the negative transfer from their mother tongue through repeated intensive training. On the other side, it should be put on the premium that students learn Chinese culture. As most quantifiers' usage concerns with Chinese cultural background, students should extend their reading horizon on Chinese history and folk culture, which would arm students with a broadened eye and multi-perspectives to understand the linguistic phenomenon. Furthermore, it is also necessary for Arabic students to establish self-confidence and look through Chinese dictionary to understand thoroughly and systematically for one specific quantifier rather than merely depend on English explanations in textbooks that designed for one specific context.

As many English explanations in HSK textbooks prefer to simplify, absolutize the semantic of quantifiers, Arabic students can hardly apply what they learn into practice in different contexts but easily get confused among synonymous quantifiers. e.g. "张” is defined in HSK textbooks as flat objects such as papers, photos; and “副” indicates facial expression. Then it would be hard for students to identify proper or not between “这张面孔 (this piece of face)” and “这副面孔(this pair of face)”. It would be better if HSK textbooks list and take examples of quantifiers in different contexts as an extending reading part after texts. This would give students tips of learning methods: They cannot depend completely on English explanations in texts, and it is necessary for them to broaden their reading lists and summarize the usage in high frequency after class. Also, it is advisable that HSK textbooks could spare a section in each chapter to analyze radicals in Chinese characters throughout the history and the usage of the same quantifiers in various contexts.

\section{CONCLUSION}

Quantifier is unique in Chinese language system and deemed as a difficult point for Chinese learning and teaching. Chinese and Arabic languages belong to two different systems which vary in expression of the concept of number and word order in grammar. Also, many quantifier collocations closely connect with Chinese image and Chinese characters, which not only demands students' accumulative knowledge towards Chinese folk culture, tradition, as well as history, but also requires them to construct a type of Chinese cognition in 
explaining linguistic phenomenon. The quantifier misuse including word order, synonymous quantifier misuse and homophonous ones implies that there still leaves room for improvement of HSK textbooks in English explanatory notes, which simplify the definition of one quantifier in absolution. It is recommended to add more English explanatory notes and create various contexts for one quantifier in HSK textbooks. Also, leaving an area for a short section to analyze radicals in Chinese characters throughout the history in HSK textbooks is a good way for Arabic students to strengthen their understanding of Chinese images as well as their memory in learning process. Furthermore, Chinese language teachers should classify quantifiers in textbooks and those used in high frequency in daily life, explain them clearly to avoid ambiguity and generalization, and then design different types of intensive practice and activities to arouse students' interests and improve their ability in precise and proper quantifier usage, thus to help them gradually eliminate the fear of difficulties during the learning process.

\section{REFERENCES}

[1] Huang Borong, Liao Dongxu: Contemporary Chinese, Beijing: Higher Education Press, 2017, p.17.

[2] Jiang Liping Ed.: HSK Standard Course, Beijing: Beijing language And Culture University Press,2014, Vol1-Vol4, 2015, Vol 5. HSK Vol 3, p160, Vol 5, p65, Vol 2, p34.

[3] Ye Liangying: A Comparion of Word Order Between Chinese and Arabic, Journal of Beijing Foreign Studies University, 2008(12).

[4] azza abdelwahab Ibrahim: Chinese Grammar Acquisition Research From the Perspective of Arabic Students, Popular Science, 2017(7).
[5] Shen Jiaxuan: Boundedness and Unboundedness, Chinese Language.1995(5).

[6] Lu Jianming: Contemporary Chinese Grammar, Beijing: Peking University press, 2019, pp.173,183.

[7] Lu Jianming: Eight Masters for Contemporary Chinese Grammar in the 20th Century, Shenyang: Northeast Normal University press, 2001, pp.146,154.

[8] Lu Bingfu: Form-Meaning Isomorphism as the Starting Point of Syntactic Analysis, Journal of Foreign Language, 2006(3).

[9] Gou Ruilong: Analysis of Quantifier “条形(Tiao Xing)" based on Syntax Cognition, Journal of Zhengzhou University, 2010(6).

[10] Niu Fangfang, Ding Chongming: Discrimination among “段(duan)”, “节(jie)”, “条(tiao)” and “件 (jian)", Modern Chinese, 2010(9).

[11] Zhang Yabing: Cognitive Semantic Analysis of Quantifiers of “对(dui)”, “双 (Shuang)” and “副 (fu)", Journal of Eastern Liaoning University, 2009(2).

[12] Gou Ruilong, Tian Mingqiu: A Study of Three Measure Words “门(men)”, “种(zhong)”, “类(lei)” in Chinese and Their Cognitive Foundation, Journal of Yunnan Normal University, 2009(3).

[13] Zhou Jingyi, Analysis and Countermeasures of Noun Classifier Error from the Perspective of Chinese and English Quantifier Comparison, Journal of Higher Education, 2017(20). 